\title{
Fast Food Industry in the Post-pandemic Era -A Case Study of KFC
}

\author{
Mushui Chen ${ }^{1}$ \\ ${ }^{1}$ Dedman College of Humanities and Sciences, Southern Methodist University, Dallas, Texas, United States
}

\begin{abstract}
The global spread of the Covid-19 pandemic exerts great influence on the global economies, and among the economic sectors which are suffering losses, the service industry, especially fast food restaurants, are greatly impacted. Before the outbreak of the Covid-19 pandemic, the fast food restaurant benefits a lot from the process of globalization, while they lose the benefit when the pandemic causes a lot of limitations on the cross-boarder flow of commodities and people. By taking KFC as an example, based on the analysis, it is found that the reasons behind such impact include slowed globalization, customer's reducing income and government bans. To help the fast food restaurants get through the difficulties amid pandemic, several possible solutions are proposed in this paper.
\end{abstract}

\section{INTRODUCTION}

Since the outbreak of the Covid-19 pandemic occurred in Wuhan, China in early 2020, more than 600 million people have been infected with the disease, and so far the death toll of the world has exceeded 700,000. In addition to great threats to people's lives, the pandemic has a huge impact on the global economy. As a matter of fact, the impact on the economy mostly comes from the loss of customers in the service industry and the reduced income expectation of consumers. In order to resume production as soon as possible and increase consumer's confidence in the economy, a number of governments have actively taken strict control measures such as issuing decrees ordering all the people stay at home and maintain appropriate social distance [2]. Specifically, with the spread of the epidemic, the British government has taken various measures to contain the spread of the virus [8]. People are encouraged to work from home and reduce unnecessary travel and such measures have played an important role in helping these countries contain the spread of the epidemic and resume production. In countries where the epidemic has been effectively controlled, many restaurants and bars have been open for customers to dine in, and consumers are also confident in the sanitary conditions at these restaurants.

However, in some countries, the epidemic has not been effectively contained. The number of the confirmed COVID-19 cases and the death tolls had been rising in the United States, and no signs of recovering from the pandemic until July. According to the present number of the confirmed Covid-19 that has been published, the confirmed cases in America accounted for 1/4 and above of the general confirmed cases in the world, and the death toll accounted for nearly $23 \%$ of the general death toll of the world. Therefore, America, as a super power, remains as one of those most seriously stricken countries in the world, which is detrimental to the consumer's confidence in and expectation for the future economy.

\section{IMPACT OF COVID-19 ON GLOBAL ECONOMIES}

\subsection{Trend of globalization}

It is undeniable that, in an era of economic globalization, driven by multinational corporations, the cross-boarder exchanges, transportations and trades of services, materials, technology, and capitals are becoming more and more frequent, and this trend of globalization has increased the global interdependence. As a result, the economies in different countries and regions become more and more dependent on each other, and a unified market is gradually taking its shape in the world. It is true that there are some shortcomings with the globalization. For example, those developing countries with weak economic power and relatively backward science and technology will become more vulnerable in the face of fierce global competition and there are more risks and challenges for them to overcome. However, the advantages of economic globalization are also obvious. As the globalization progresses, more and more essential productive factors can be freely circulated on a global scale. During this process, some international organizations are established, striving to build a fair and transparent environment where all the enterprises can compete equally and effectively. Specifically, for the fast food industry, they can spend less money to buy more high-quality products, or they can open stores in different countries and regions around the world and increase the

masonchen@mail.smu.edu 
company's global reputation and profits. Under the trend of globalization, fast food restaurants can also be more flexible in their operations. For instance, they can open stores in those countries or regions where there is market demand for the fast food [1]. Fast food industry can benefit from all of these and the wave of globalization, which cannot be ignored.

\subsection{Impact of Covid-19 on Global Economy}

The spread of the Covid-19 pandemic is accelerating its pace on a global scale. Undoubtedly, due to the strict control measures by the governments on transportations, import and export practices, the process of globalization will be affected. In details, the economic growth will slow down, and the international trade and investment will shrink. The most direct consequence also includes the sharp decline in global manufacturing output, and the service industry will be affected accordingly. More importantly, the global supply chain will be to some extent undermined. As estimated by International Monetary Fund (IMF) that, the growth rate of the world economy in 2020 will be $3.2 \%$, which is 0.1 percent lower than the estimated they made in January. Organization for Economic Co-operation and Development (OECD) predicted that the global economic growth in 2020 would be $2.4 \%$, which was much lower than the prediction they made before the outbreak of pandemic, that is, $2.9 \%$. According to Goods Trade Barometer lately released by World Trade Organization (WTO), as of February, the real-time index that reflected the global trade tendency was 95.5, which was lower than the reference value 100 . If the impact of the pandemic is considered, the index value might be even lower. The flow of people and goods will be subject to certain limitations [7], and so far, more than 140 countries and regions have taken immigration control measures against China and more than 100 countries and regions have taken immigration control measures against South Korea. What is more, Chinese consumer's demand will be further reduced amid the pandemic, and the import of bulk commodity from other countries will be further limited. It is quite clear that, the safety of global supply chain is threatened, and as one of most important countries at the Global production network, China's industrial activity will decline sharply, which will impose adverse impact on the related industries in other countries. Japan and South Korea are two important economies at the global industrial chain, and they occupy high market shares in the fields such as semiconductors, automobile and chemical materials etc. However, due to the rapid spread of the pandemic, some of enterprises in Japan and South Korea have been shut down, which imposes greats threat to the stability of global supply chain.

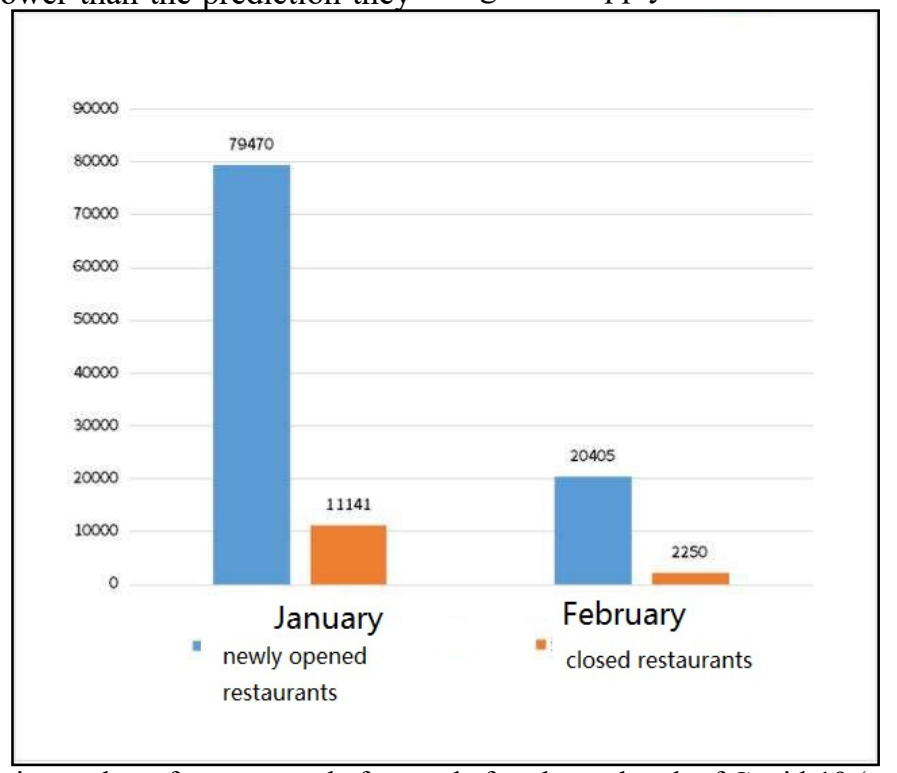

Figure 1. Changes in number of restaurants before and after the outbreak of Covid-19 (as of Feb. 29, 2020) *Data source: Enterprise Database (professional)

Therefore, as the Covid-19 pandemic stops the process of globalization to some extent, many enterprises and manufactures are faced with a lot of problems such as decline in profits and difficult operation. Among all of these effects, the most direct consequence is that the consumer's income expectation is reduced, as the consumers would have concern about the economic development when they have a presentiment that there will be an economic crisis. Therefore, in addition to the concerns about getting infected, due to the lowered income expectation and the economic uncertainties, the consumers would rather save money than to spend their money on the restaurants. In other words, as the process of globalization is blocked, either directly or indirectly, the catering industry will be greatly impacted amid the pandemic.

\section{Case Study of KFC}

KFC (Kentucky Fried Chicken) is a fast food company affiliated to Parkson Retail Group, and its company business mainly include providing eat-in services, and the impact of the pandemic on Yum Brands continues to expand. Following shutting down one third of global 
restaurants, it is reported that, Yum Brands has temporally closed a number of KFC restaurants in the world, as the impact of pandemic on the company continues [4]. Previous to this, Yum Brands once made an announcement that, it might suffer from loss from operations during the first quarter of this year, because its sales and production capacity would be affected by the pandemic, and they also said that Yum Brands has temporarily closed nearly one third restaurants around the world. According to the company, due to the shortened business hours and the reduced number of consumers, since the Spring Festival holiday, the same-store sales of the restaurants still open have been reduced by 40 to $50 \%$ on a year-on-year basis. To better understand the mechanism with which the Covid-19 pandemic affects the catering industry, it is necessary to figure out the specific reasons behind these influences from the perspective of KFC. Therefore, the author is going to state the reasons one by one.

\subsection{KFC's reduced advantage as a multi-national company}

With the global spread of Covid-19 pandemic, the fragility of supply chain and distribution network in the economic globalization becomes evident. In the past, through the global supply chain, multinational corporations such as KFC was capable of organizing production and sales around the world so as to reduce the cost of production by making use of their comparative advantages. Thanks to the integrated operations and rapid response at the supply chain, those international fast-food companies, such as KFC enjoys great convenience and transparency when they coordinate their materials, information and values. However, the outbreak of pandemic hampered KFC's just-in-time system, and many governments took more stringent measures of control in terms of the transportation and the flow of people. In the era of economic globalization, the global division of labor becomes even more complicated, and enterprises at the global supply chain and value chain are developing closer relationship with each other. The stagnation of production in one country will affect the entire industrial chain, so the stalled process of globalization is one of enormous challenges that face KFC. Either in terms of food cost, transportation expenses, rent or salaries, KFC will lose its advantages in the process of globalization before the outbreak of pandemic. Simultaneously, different governments issued decrees controlling the import and export commodities or set limits on the exit and entry, and all these measures are not good news for KFC operation.

\subsection{KFC's market demand is reduced}

Basic economic sectors are suffering from direct impact in many countries due to the spread of pandemic around the world. The global consumption, investment and trade are impeded, and the global aggregate demand is shrinking. KFC is no exception, as the household consumption is directly affected by the quarantine measures. Those consumers who loved to dine in KFC restaurants before the outbreak had to obey the government orders and stay at home. Meanwhile, with the impact of pandemic, the residents felt pessimistic about the employment opportunities and incomes in the future. As a result, the consumer's confidence indicators are declining significantly, and the decline level is close to that during the financial crisis of 2008. Due to these factors, the number of KFC customers are dropping dramatically.

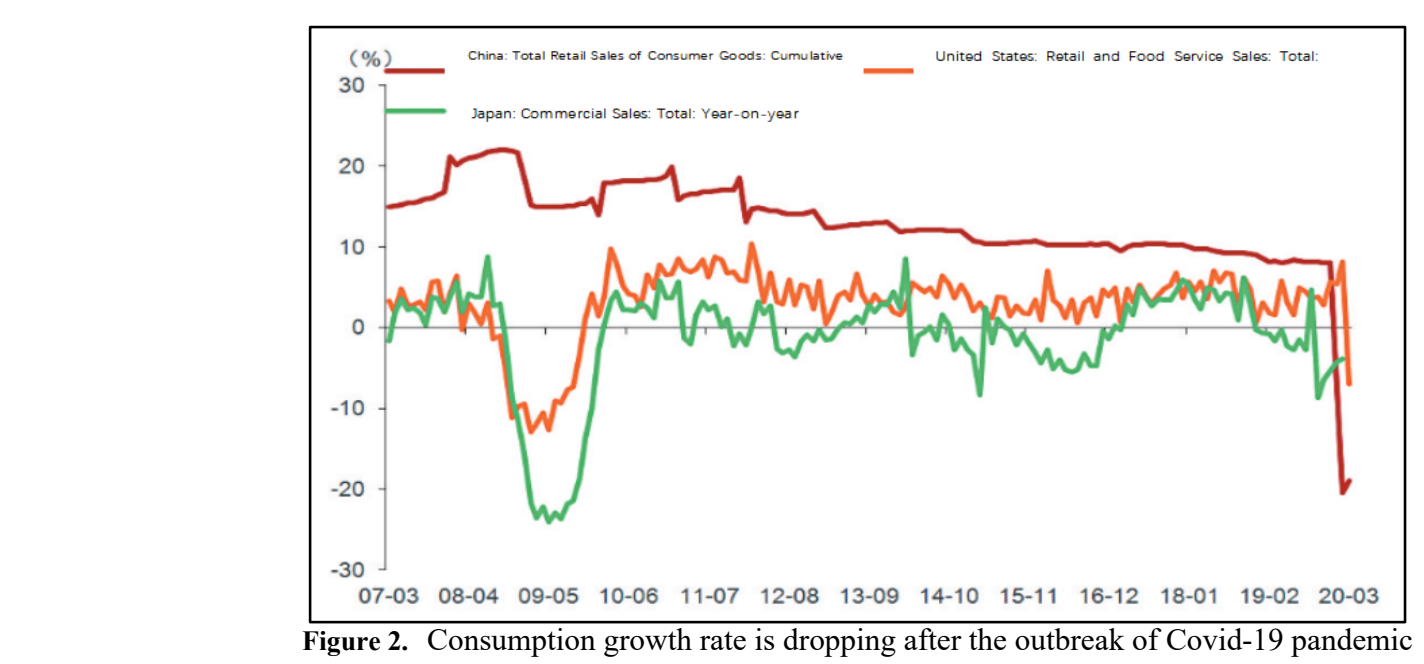

*Data source: Wind, Research Institute of Bank of China

\subsection{Declining Consumers' Confidence}

Since the outbreak of Covid-19 pandemic, there is a wide concern among the consumers of fast food restaurants about the future. From figure 3, it can be found that, most respondents expressed their worries about the future, and those respondents who feel panic also ranked top in terms of their numbers. They are afraid of losing their jobs, getting infected or robbed by the rioters, and all these worries and concerns would reduce people's consuming behaviors, as they started to save money.

Because of wide lockdown in service industry is enforced by the government, many consumers who are actually working for restaurants, cinemas and shopping malls are actually losing their jobs. Consequently, their 
income expectation and confidence in the economy are actually showing downward trend. This phenomenon will be extremely detrimental to the fast food business such as KFC, when their potential consumers become concerned about their futures and then start to deposit money.
Moreover, it is well known that fast food store such as $\mathrm{KFC}$ is a crowded place where people sit close to each other and share their foods, which makes the store a quite risky place for virus transmission.

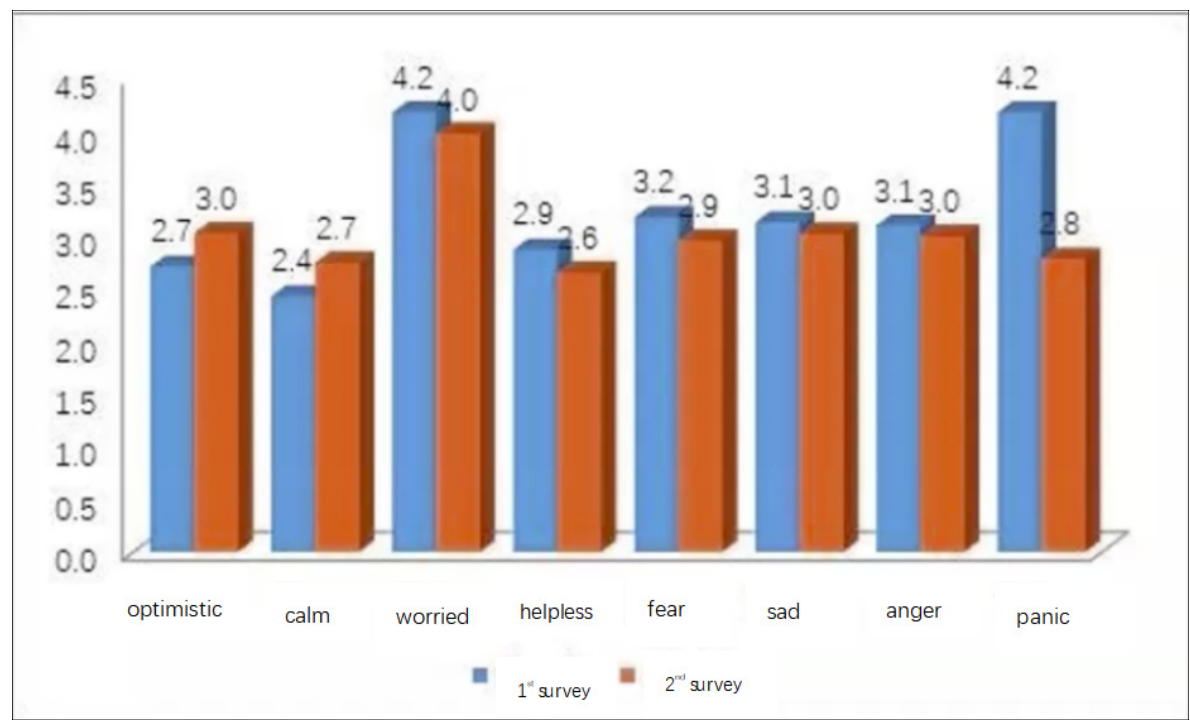

Figure 3. Investigation on social mentality during the pandemic

*Data source: research center of social psychology, Institute of Sociology, Chinese Academy of Social Sciences

\section{Possible Solutions}

Based on the above analysis, we are going to propose several possible ways in which the fast-food industry can resume operations in the post-epidemic era.

First of all, reduced eat-in service is recommended for the catering industry, and it is suggested that fast food restaurants explore more channels for selling takeaways, for example, they can encourage consumers to order food online through social media, app and chat tools [6]. Online meal booking is quite convenient, and more importantly, the social distance can be maintained by ordering food online. Moreover, it helps the fast food restaurants improve their turnover amid the pandemic. However, when delivering the food, the fast good restaurants should pay attention to the sanitary issues and make sure that the take-away deliveryman wear masks and gloves and disinfect the food package so that the consumers will not worry about the safety of take-away [5].

Secondly, the fast food restaurants should implement stringent sanitation management measures, and make sure that the cleaning works are well done, and by doing so, their good social image can be established, and they can also regain consumers' confidence. Moreover, the fast food restaurants are encouraged to open the restaurants when they are well prepared. For instance, special personnel should be arranged responsible for disinfecting and cleaning work to make sure that the restaurant is clean and sanitary. It is suggested that all the seats in the restaurant should be kept at least 1 meter apart or the segregation boards should be set between the seats, as these measures can effectively help maintain social distance. If possible, hand sanitizer could be provided and air cleaner could be used in the restaurants, so that the customers would have less worries about the sanitation issues when they find these in the restaurants [3].

Finally, from the angle of general operation, it is suggested that some measures are taken to reduce the operating costs of restaurants. For example, the restaurant could talk with the landlord to ask for deferred payment or rent reduction. In addition, the restaurants could adopt some measures to reduce the personnel cost. During the pandemic, most of eateries are shut down, and some of them provide takeaways. When the pandemic is controlled and some eateries are open for business, it is quite possible that customers feel reluctant to dine out. if this is the case, the demand for takeaways are going up. Therefore, during the period, the restaurant should re-arrange the personnel and reduce the personnel cost. Possible measures include adopting daily wage or hourly wage and talking with the employees over the wages during pandemic.

\section{Conclusion}

In general, based on the above analysis, the following conclusions are drawn. First, it is quite apparent that the pandemic is causing great impact on the real economies, and among them, due to the special vulnerability of fast food restaurants, great economic losses are occurred, which is quite inevitable. Second, the reason behind such vulnerabilities include slowing down of globalization, lockdowns, reduced consumer's confidence in the economic prospects, and negative emotions among them, etc. Based on the analysis, several possible solutions are proposed, including providing online meal ordering 
service, implementation of sanitation management measures and reduction of the operating costs of restaurants. Nevertheless, there are some deficiencies with the present study as the influences of the Covid-19 pandemic on countries all over the world are quite different, so microcosmic study of fast food industry in a special market is recommended to gain further insight into the economic performance under the pandemic.

\section{ACKNOWLEDGMENT}

First, I would like to extend thanks to the teachers who gave me a lot of useful advice and guided me through the paper writing. Their advice are both inspiring and helpful, without which I can't complete the paper smoothly. Second, I owed a great deal to my family as they warmly encouraged me when I was doing the researches. With their encouragement, I have the drive to complete the paper.

\section{REFERENCES}

1. Anonymous, How is COVID-19 affecting retail, restaurants? Consulting - Specifying Engineer, Jun 2020, Vol.57(5), pp.48-49, 2020.

2. C. Courtemanche, Strong Social Distancing Measures In The United States Reduced The COVID-19 Growth Rate. Health Affairs, Jul 2020, Vol.39(7), pp.1237-26, 2020.

3. J. Lu, COVID-19 Outbreak Associated with Air Conditioning in Restaurant, Guangzhou, China. Emerging Infectious Diseases, Vol.26(7), pp.1628-1631, 2020.

4. N. Luna, COVID-19 outbreak forces Yum Brands to close 7,000 global restaurants. Nation's Restaurant News, Mar 25, 2020

5. J. Hough, What I Did During The Market Meltdown. Barron's, Vol.100(10), p.13, 2020.

6. J. Wohl, THE NEW REALITY FOR RESTAURANTS. Advertising Age, Vol.91(6), p.12, 2020.

7. M. Kraemer, The effect of human mobility and control measures on the COVID-19 epidemic in China. Science, Vol.368(6490), pp.493-497, 2020.

8. R. Ogden, The passage of time during the UK Covid-19 lockdown. PLoS One,Vol.15(7), p.e0235871, 2020. 